\title{
TRACEABILITY SYSTEM FOR AGRICULTURAL PRODUCTS BASED ON RFID AND MOBILE TECHNOLOGY
}

\author{
Koji Sugahara \\ National Agricultural Research Center, National Agriculture and Food Research \\ Organization, 3-1-1 Kannondai, Tsukuba,305-8666, Japan
}

Abstract: In agriculture, it is required to establish and integrate food traceability systems and risk management systems in order to improve food safety in the entire food chain. The integrated traceability system for agricultural products was developed, based on innovative technology of RFID and mobile computing. In order to identify individual products on the distribution process efficiently, small RFID tags with unique ID and handy RFID readers were applied. On the distribution process, the RFID tags are checked by using the readers, and transit records of the products are stored to the database via wireless LAN. Regarding agricultural production, the recent issues of pesticides misuse affect consumer confidence in food safety. The Navigation System for Appropriate Pesticide Use (Nouyaku-navi) was developed, which is available in the fields by Internet cell-phones. Based on it, agricultural risk management systems have been developed. These systems collaborate with traceability systems and they can be applied for process control and risk management in agriculture.

Key words: food safety, traceability system, risk management, RFID, mobile devices

\section{INRTODUCTION}

In recent years, Japanese people have been increasingly aware and concerned about food safety issues. This is a result of various incidents relating to the food safety since 1996. Examples of such incidents are food poisoning by bacteria of E. coli $\mathrm{O} 157$ and Vibrio parahaemolyticus, largescale food poisoning on the processed milk, mixing of genetically modified

Please use the following format when citing this chapter:

Sugahara, K., 2009, in IFIP International Federation for Information Processing, Volume 295, Computer and Computing Technologies in Agriculture II, Volume 3, eds. D. Li, Z. Chunjiang, (Boston: Springer), pp. 2293-2301. 
corn (GMO) in the processed food, pesticide residue on the imported frozen vegetable products, uses of the illegal agricultural chemicals, and product recalls caused by pesticide misapplications. The first cow infected with BSE (bovine spongiform encephalopathy) in Japan was discovered in 2001, and the import of beef from USA was stopped in 2003 because the BSE cow had discovered there. Many other issues on meat products have occurred such as the false labeling. Moreover, the outbreak of bird flu in Japan and East Asia was reported in 2004. Therefore, many consumers feel insecure in the safety of agricultural products including imported ones.

In this paper, current state and perspective of the researches on food safety, especially ICT-based food traceability system in Japan are presented. The policy that has been promoted by the Japanese Government to improve food safety and to establish food traceability systems is outlined. Moreover, the integrated traceability system for agricultural products and the agricultural risk management system are introduced as the research works that the author has been involved in.

\section{POLICY FOR FOOD SAFETY}

\subsection{Policy of the Japanese Government}

The Japanese Government enacted the Food Safety Basic Law in May 2003. The purpose of this law is to promote the measure concerning food safety. The Food Safety Commission was organized in July 2003, based on the law. This organization aims to undertake scientific risk assessment about foods and their effects on human health, and it is independent from the organizations that implement risk management.

The Ministry of Agriculture, Forestry and Fisheries (MAFF) announced "regeneration plan of food and agriculture" in April 2002 and "policy outline of food safety and security" in June 2003. Securing food safety is positioned as an important theme of the policy. MAFF are implementing the measures such as support system for producers, information provision to consumers, and risk management on food production. Promotion of development and introduction of "food traceability systems (FTS)" has been carried out as one of those measures (Tomiyama, T., 2005).

\subsection{System Development}

Table 1 shows the institutional FTS in Japan. The beef traceability system based on the Beef Traceability Law (December 2003) is mainly for domestic beef as the measure for the BSE problem. The food traceability systems are 
for various food products to support independent activities, however there is not legal obligation to use the systems and to store the products' information. In the campaign to record production processes of whole food products for the producers around Japan, there is effort obligation to record the items based on the Food Sanitation Law. The system of production information disclosure as JAS (Japan Agricultural Standards) is for beef, pork and farm products, in order to provide production information of the products with the JAS marks to consumers.

MAFF is promoting development of FTS to establish food traceability and safety. The budgets for development, demonstration and introduction of FTS have been offered to the private sector since 2001. The feature of these projects is to utilize ICT, especially "ubiquitous computing" by the u-Japan Strategy, and to develop not only FTS but risk management systems for agriculture and food industry. "Ubiquitous computing" technology enables anyone easily to access various information anytime and anywhere, and it has shown remarkable progress with the spread of RFID and mobile devices. MAFF has required the FTS development with the following features: a) speed-up of callback and cause unfolding at food accidents, b) efficiency improvement of food production and distribution, c) enhancement of various food information that is provided to consumers.

This measure has prompted the establishment of FTS and systems to disclose information about food production and distribution processes. The local governments and the agricultural cooperatives (JA) as well as the Japanese government have been actively promoting development and practical introduction of FTS in the national projects.

Table 1. Institutional food traceability systems in Japan.

\begin{tabular}{lll}
\hline \multicolumn{1}{c}{ System Name } & \multicolumn{1}{c}{ Target } & \multicolumn{1}{c}{ Record items } \\
\hline \multirow{2}{*}{ The beef traceability system } & Domestic beef & $\begin{array}{l}\text { Date of birth, sex, type, breeding location, } \\
\text { breeding manager }\end{array}$ \\
\cline { 2 - 3 } The food traceability systems & $\begin{array}{l}\text { Foods other than } \\
\text { domestic beef }\end{array}$ & $\begin{array}{l}\text { The producers or the corporations independently } \\
\text { set recorded data }\end{array}$ \\
\cline { 2 - 3 } $\begin{array}{l}\text { The campaign to record } \\
\text { production processes }\end{array}$ & $\begin{array}{l}\text { The items based on Food Sanitation Law (effort } \\
\text { obligation) }\end{array}$ \\
\cline { 2 - 3 } $\begin{array}{l}\text { The system of production } \\
\text { information disclosure (JAS) }\end{array}$ & $\begin{array}{l}\text { beef, pork and farm } \\
\text { products }\end{array}$ & $\begin{array}{l}\text { Animal medicines, agricultural chemicals, } \\
\text { fertilizers, and so on }\end{array}$ \\
\hline
\end{tabular}

\section{BASIC TECHNOLOGIES}

\subsection{Scheme of Food Traceability}

As the basic scheme of ICT-based FTS, "Virtually Identified Produce System (VIPS)" (http://www.vips.gr.jp/) was developed (Sugiyama, 2001). 
National Agriculture and Food Research Organization (NARO) owns the business model patent of this system (Japanese patent No. 3355366). Regarding VIPS, an identification data (ID) is assigned to an identification unit (lot) of food products and it is printed on the products' labels or packages. The producers input production data of their products and send these data to the Internet-accessible database server. The consumers can browse the products' data by accessing the website of VIPS and entering the products' ID. Based on VIPS, a practical information disclosure system for farm products, "SEICA" (http://seica.info/) was developed and open to the public in 2002 (Sugiyama, 2004).

\subsection{RFID and Mobile Technology}

For the practical traceability systems, it is important to apply automatic identification technology such as barcode system. RFID (Radio Frequency Identification) is innovative noncontact automatic identification technology to read and write the data on electronic media (IC chips) more quickly and accurately. It has been applied mainly to logistics of industrial products in order to identify the products and check their distribution processes. RFID has recently shown promise for more advanced and effective FTS.

Mobile technology is based on wireless networking as cell-phone service and wireless LAN (mainly Wi-Fi). In Japan, recent models of cell-phones have increased range of functions such as camera and Internet access, and such "Internet cell-phones" have been very familiar ICT tools. On the other hand, high-speed wireless networks have been easily available around the Wi-Fi access points (hotspots) in various places and facilities, using mobile devices such as laptop PC, PDA, and portable game consoles.

\section{TRACABILITY SYSTEM}

\subsection{Integrated Traceability System}

In the FTS research project that the author has been involved in since 2003, an integrated traceability system for agricultural products in the food chain have been developed, based on the technologies of network computing, cell-phones, and RFID (Sugahara, 2005). Figure 1 shows the concept of this system. It consists of three subsystems: a production record system using Internet cell-phones, a distribution record system using RFID devices, and an information disclosure system for consumers on WWW (World Wide Web). The production record system has been improved as an agricultural risk management system, as described later. 


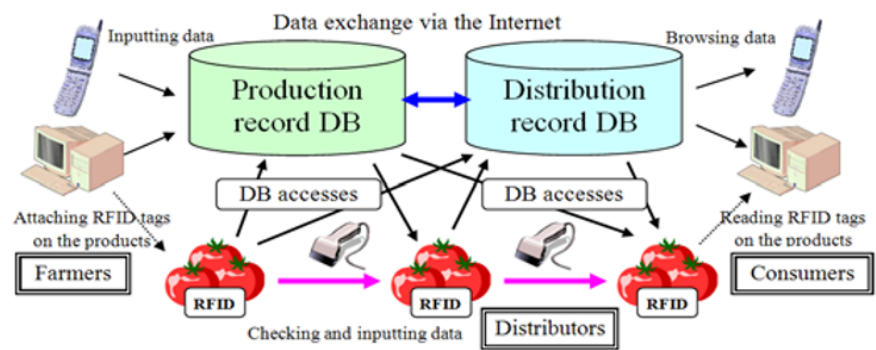

Figure 1. The concept of the integrated traceability system for agricultural products based on RFID and mobile technology, to record and check the data on the production and distribution processes.

\subsection{Distribution Record System}

A key concept to record distribution processes as the food chain is that a temporal identification unit is an "event" which is recorded at each specific point of the distribution process, such as incoming, outgoing, combination, and division. Data of an event record consist of an event ID assigned to each event, a point ID, event time, and involved product lot IDs. Based on this concept, a database and a data-inputting system were designed.

The on-site data-inputting system based on RFID was developed in order to identify the product lots and record the "event" at each point of the distribution process efficiently and quickly. RFID tags which have unique ID to identify individual lots and handy RFID reading devices (readers) compatible with Wi-Fi to read the ID were applied (Figure 2). Additionally, an Internet-accessible database server was built. It can store the data which are sent from the readers and it enables to retrieve and refer the distribution process records on WWW.

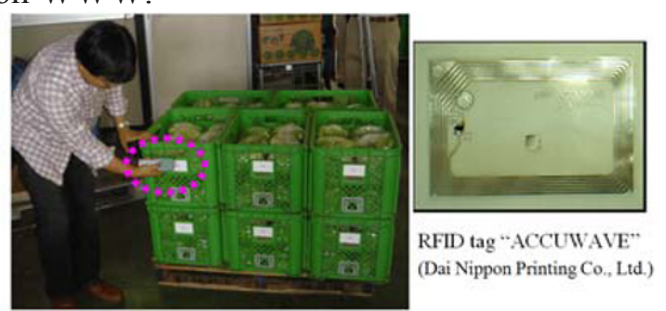

Figure 2. Reading the RFID tags attached to the container cases by using a handy reader in the experiment on lettuce products.

\subsection{Information Disclosure System}

In order to disclose proper information about agricultural products to consumers, information disclosure systems has been developed based on 
VIPS and additionally applying "QR code" (Denso Wave Inc.) which is a kind of two-dimensional (2D) barcode system. In Japan, camera-equipped Internet cell-phones have been very popular and most of them have a barcode-reading function. Therefore, the consumers that purchase the products with the $\mathrm{QR}$ codes can immediately browse and check the information about the products' production and distribution, by reading the QR codes using their own cell-phones (Figure 3).

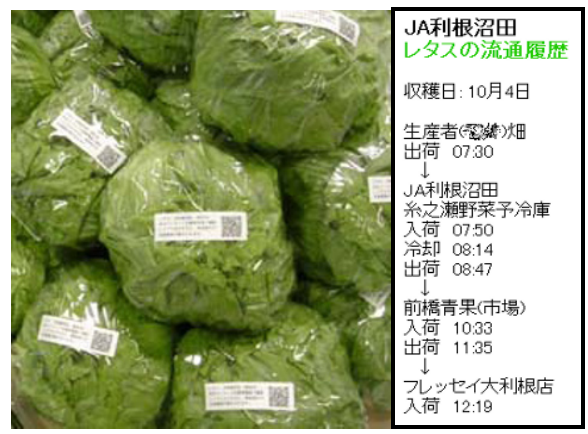

Figure 3. Lettuce products for sale which the "QR code" labels are pasted on (left) and a display of the distribution records on a cell-phone (right).

\subsection{Field Experiments}

In order to verify the effectiveness of the integrated traceability system in the actual food chain of vegetable and fruit products, the field experiments of the system were carried out in Yamagata, Saitama, Shizuoka, and Gunma from 2003 to 2005, in cooperation with farmers, agricultural cooperatives, wholesale markets, cooperative societies (co-op), supermarkets and the local governments. Regarding RFID, "mu-chip" (Hitachi, Ltd.) as microwave-type tags $(2.45 \mathrm{GHz})$ and "ACCUWAVE" (Dai Nippon Printing Co., Ltd.) as electromagnetic-type tags $(13.56 \mathrm{MHz})$ were applied. In these experiments, the information disclosure on the products was well received by consumers. However it was required to improve workability of data inputting and RFID handling.

\section{AGRICULTURAL RISK MANAGEMENT}

\section{$5.1 \quad$ Nouyaku-Navi}

The recent issues on agricultural chemicals (AC) misuse and residue on the agricultural products have affected consumer confidence in food safety. 

Mobile Technology

It is required for farmers to make proper uses of $\mathrm{AC}$ to their products. In the research project supported by MAFF, Navigation System for Appropriate Pesticide Use was developed as a basic system for agricultural risk management (Nanseki et al., 2005). It was called "Nouyaku-navi" (Nouyaku is the Japanese word for AC including pesticide). Its main part is composed of a database of the legal standard for the registered $\mathrm{AC}$ uses and a server application to judge whether each AC use is appropriate for the standard or not, as a Web-based system which is accessible by Internet-enabled PC and cell-phones. This system has the following functions: creation of guidelines and rules on pest control, creation and judgment of AC application plans, onsite warning and recording of AC applications, and so on. Figure 4 shows a flow of using the application of Nouyaku-navi.

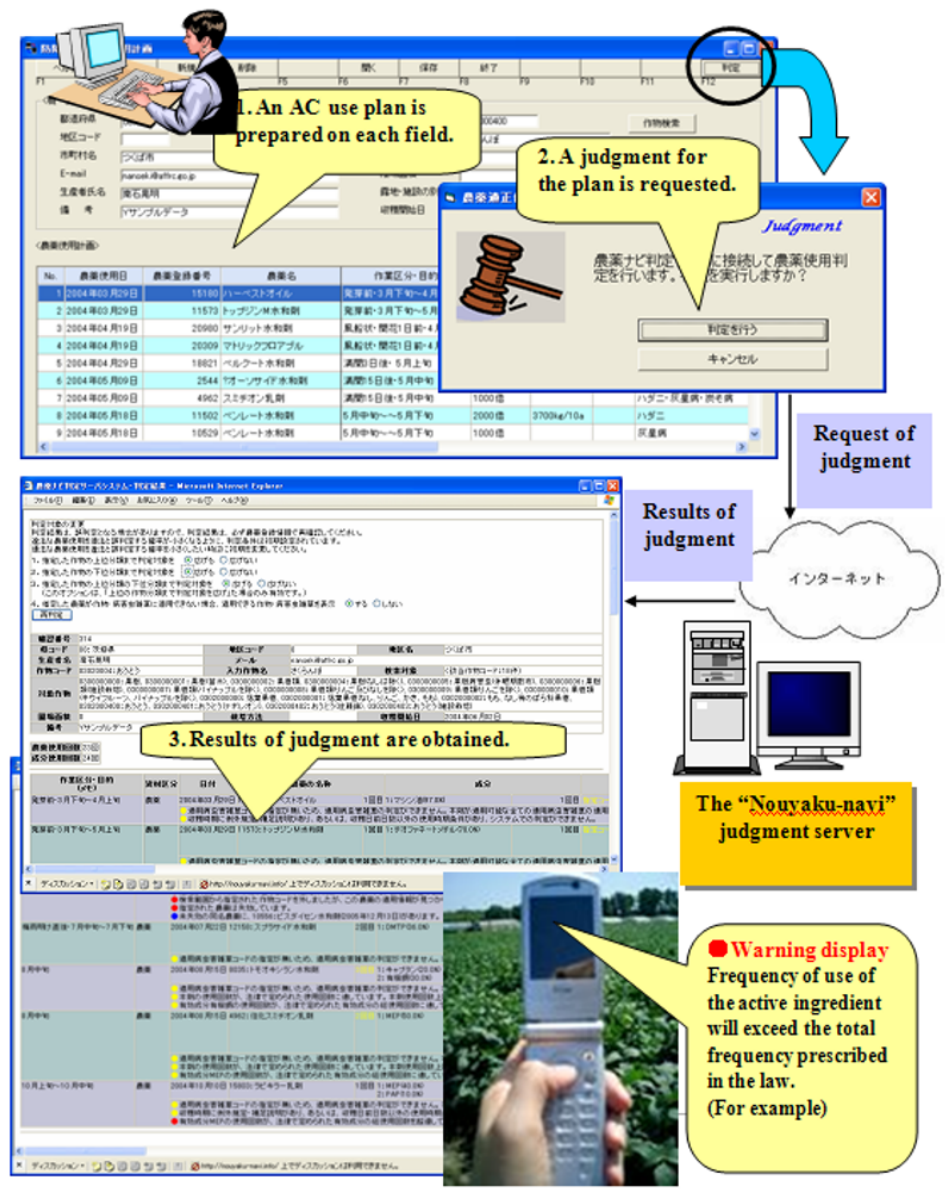

Figure 4. A flow of using the application of "Nouyaku-navi". 


\subsection{Risk Management System}

Some of existing "food traceability systems" also have function to check AC application records on the products. Although they can check whether the AC applications are appropriate after the application or the harvest, they can not prevent $\mathrm{AC}$ misapplication due to carelessness before the application.

Based on Nouyaku-navi, a risk management system on AC applications was developed in part of the national project by MAFF (Nanseki et al., 2006). The main feature of this system is that it is possible to check whether AC applications on individual products are appropriate for multiple standards and at multiple stages such as planning, application, harvest, distribution and sale. This system can prevent AC misapplication by checking before the application, and it can record the detail data $(5 \mathrm{~W} 1 \mathrm{H})$ of the AC application while checking it. The system was tested and evaluated practically in the agricultural cooperatives in Yamagata. Effectiveness of the method to check on the multi-standards and multi-stages has been confirmed.

Moreover based on this system, an integrated ICT system for agricultural risk management and traceability on vegetable and fruit production were developed and released by the Nogyo Navigation Laboratory in September 2007 (http://www.nnavi.org/). This system has been utilized practically in farms and agricultural cooperatives around Japan.

\section{CONCLUDING REMARKS}

In Japan, various ICT-based food traceability systems (FTS) have been developed and introduction of them into agriculture and food industry has been promoted, in order to deal with consumers' interest in food safety and security. However, FTS have not spread enough because the benefits to introduce those ICT systems are not clear for the food industry. They would need to be applied not only for traceability but for process control, quality control and risk management, such as Good Agricultural Practice (GAP).

Regarding the ICT systems to manage product distribution and sale, although applying RFID is efficient and effective, the problems are cost to utilize RFID tags and devices, and workability of RFID handling such as tagging and reading. To solve these problems, the researchers are studying how to reduce the cost and how to automate RFID handling. Although the information disclosure on the products was well received by the consumers, it was difficult for them to understand details of the shown data. It is important to research what kind of information the consumers require.

A goal of the agricultural risk management system is to enable workers automatically to prevent mistakes in various agricultural operations such as $\mathrm{AC}$ applications. Moreover, by collaboration of the risk management system 
and FTS, it is expected that safety and security of agricultural products will be further improved.

\section{ACKNOWLEDGEMENTS}

The author would like to thank Professor Teruaki Nanseki, Kyushu University, Dr. Kazunori Sato, Dr. Masayuki Hirafuji and Dr. Seishi Ninomiya, National Agricultural Research Center, for their cooperation and helpful advices. This work was supported in part by a research project for utilizing advanced technologies in agricultural, forestry and fisheries of Agricultural, Forestry and Fisheries Research Council, MAFF.

\section{REFERENCES}

Nanseki, T., 2005. A navigation system for appropriate pesticide use and food safety, Proceedings of International Seminar on Technology Development for Good Agriculture Practice in Asia and Oceania: 134-152

Nanseki, T., 2007. Status and Perspective of Food Traceability in Japan, Proceedings of International Food Traceability Symposium -Korea, Japan, EU-

Nanseki, T., et al., 2005. A navigation system for appropriate pesticide use: design and implementation, Agricultural Information Research, 14(3): 207-226 (in Japanese)

Nanseki, T., et al., 2006. Development of a risk management system for agricultural chemical use, Agricultural Information Research, 15(4): 359-372 (in Japanese)

Sugahara, K., 2005. Traceability system for agricultural products using RFID and mobile technology. Proceedings of International Seminar on Technology Development for Good Agriculture Practice in Asia and Oceania: 204-212

Sugahara, K., et al., 2006. Effective distribution traceability system for agricultural products based on RFID technology. Proceedings of AFITA 2006: 424-431

Sugiyama, J., 2001. Virtually Identified Produce System (VIPS) using the Internet. Agriculture and Horticulture 76(8): 845-854 (in Japanese)

Sugiyama, J., 2004. Traceability and accountability for produce. Journal of Agricultural Science 59(5): 193-197 (in Japanese)

Tomiyama, T., 2005. Introduction spread of food traceability, Y. Niiyama [ed.] Traceability in Food Chain, Showado: 114-126 (in Japanese) 